\title{
Sağlık Çalışanlarının Riskli Gebelikler Eğitimi Etkinliğinin Değerlendirilmesi
}

\section{Evaluation of the Effectiveness of Risky Pregnancies Education for Healthcare Professionals}

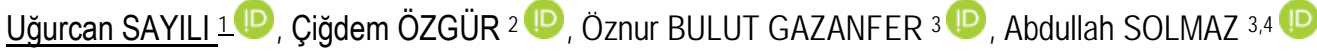 \\ 1 Karaköprü İlçe Sağlık Müdürlüğü, Şanlıurfa, Türkiye \\ 2 Viranşehir İlçe Sağlık Müdürlüğü, Şanlıurfa, Türkiye \\ 3 Şanlıurfa İ Sağlık Müdürlüğü, Halk Sağlığı Hizmetleri Başkanlığı, Şanlıurfa, Türkiye \\ 4 Harran Üniversitesi, Tıp Fakültesi, Çocuk Sağlığı ve Hastalıkları Anabilim Dalı, Şanlıurfa, Türkiye
}

Öz.

Amaç: Bu çalışmanın amacı sağlık personellerinin riskli gebelikler konusunda bilgi düzeylerini belirlemek ve eğitim öncesi ile sonrası bilgi düzeylerinin karşılaştııılarak gerçekleştirilen eğitimin etkinliğini değerlendirmektir.

Materyal ve metod: Bu çalışma 2020 yılında Şanlıurfa'da, Şanlıurfa il Sağlık Müdürlüğü ve Dünya Sağlık Örgütü (DSÖ) iş birliğinde gerçekleştirilen "Suriyeli Sığınmacı ve Türk Vatandaşı Kadınlarda Riskli Gebeliklerin Tanı ve Takibi" projesi kapsamında yürütülen bir eğitim müdahale çalıșmasıydı. Calıșmanın evrenini Șanlıurfa'daki Ilıçe Sağlık Müdürlüklerinde çalışan 26 hekim ve 26 ebe/hemşire oluşturmaktaydı. Evreni oluşturan 52 sağlık personeli olmasına rağmen bu personellerin bir kısmı Covid-19 pandemisinde de görev aldığı ç̧in çalışma sonunda 41 sağık personeline eğitim verildi. Katılımcılara eğitim öncesi ve sonrası anketler uygulandı. Eğitim öncesi ve sonrası bilgi düzeylerindeki değişim karşılaştırıarak eğitimin etkinliği değerlendirildi.

Bulgular: Katılımcıların \%43,9'u (n:18) doktor, \%41,5'i (n:17) ebe, \%14.6'sı (n:6) hemşire olarak görev yapmaktaydı ve katılımcıların meslekteki tecrübe ortancası 2 yıldı (min:3 ay- max:28 yı). Çalışmamıza katılanların \%31,7'si mesleki eğitimi boyunca riskli gebelik konusunda eğitim almadığını belirtti. Mezuniyeti sonrasında eğitim aldığını belirtenlerin oranı ise \%12,2'ydi. Calıșmaya katılan sağlık çalışanlarının \%90,2'si (n:37) riskli gebeler için gebe sınfı eğitiminin gerekiliğine katıldığını belirtti. Eğitim sonrasında otuz soru için de doğru cevap yüzdelerinde artı̧ görüldü. Otuz sorudan 22'sinde doğru yanıtlarda \% $15-73$ arasında istatistiksel olarak anlamlı düzeyde artı̧ $(p<0.05) ; 8$ soruda ise istatistiksel olarak anlamsız bulunsa da doğru yanıtlarda \%10-15 arasında artış görülmektedir ( $p>0.05)$.

Sonuç: Bilgi düzeyinde 30 sorunun 22'sinde anlamlı düzeyde artış, 8'inde anlamlı olmayan artış bulundu. Bilgi düzeylerinde artış görüldüğü için eğitim müdahalesi etkili bulunmuştur. Gebe sınıfı eğitimlerini gerçekleştirecek birinci basamak sağık ekiplerine yönelik verilecek eğitimlerle sağık profesyonellerinin bilgi, beceri ve uygulamalarını geliştirmek mümkündür.

Anahtar Kelimeler: Riskli Gebelik; Eğitim, Etkinlik; Sağlık Çalışanı

Abstract

Background: The aim of this study is to determine the knowledge level of healthcare professionals on risky pregnancies and to evaluate the effectiveness of the education by comparing the pre-and post-education knowledge levels.

Materials and Methods: This study was an educational intervention study carried out within the scope of "Diagnosis and Followup of Risky / High Risk Pregnancies of Women in Syrian and Host Communities" project in cooperation with the Sanliurfa Provincial Health Directorate and the World Health Organization (WHO) in Şanlıurfa in 2020. The study population consisted of 26 physicians and 26 midwives / nurses working in the District Health Directorates in Sanliurfa. Although the study population included 52 healthcare professionals, some of these also had a role in Covid-19 pandemic and 41 healthcare professionals were educated and pretest-posttest questionnaires were applied before and after education. The effectiveness of the education was evaluated by comparing knowledge levels of pretest-posttest.

Results: $43.9 \%$ (n:18) of the participants were doctors, $41.5 \%$ (n:17) were midwives and $14.6 \%$ (n:6) were nurses. The participants had 2 years of median professional experience (min:3 months-max 28 years). $31.7 \%$ of the participants in our study stated that they did not receive any education on risky pregnancies during their vocational education. The rate of those stating that they received education after graduated was $12.2 \% .90 .2 \%$ ( $n: 37$ ) of the healthcare professionals participating in the study stated that Pregnant Classroom Education was necessary for women with risky pregnancy. In general, there was an increase in the percentage of correct answers in all questions. \%15-73 increase in correct answers was found to be statistically significant in 22 questions $(p<0.05)$ and statistically insignificant $10-15 \%$ increase in correct answers in 8 out of 30 questions was observed $(p>0.05)$.

Conclusion: The significant increase was found in 22 of 30 questions and insignificant increase in 8 of 30 in knowledge level. Therefore, the education intervention was found to be effective. It is possible to improve the knowledge, skills and practices of healthcare professionals with the education to be given to primary health care teams who will carry out pregnancy class educations.

Key words: Risky Pregnancy, Education, Effectiveness, Healthcare Professional

\section{Sorumlu Yazar I \\ Corresponding Author}

Uzm. Dr. Uğurcan Sayılı, Halk Sağlığı Uzmanı,

Karaköprü Illçe Sağlık Müdürlüğü, Atakent Mahallesi, Atatürk Blv. No:59, 63320

Karaköprü/Şanlıurfa, TÜRKIYE
Tel: +90 5318446359
+904143187342
Fax: +90 4143519447

e-mail: ugurcan.sayili@istanbul.edu.tr

Geliş tarihi / Received:

10.10.2020

Kabul tarihi / Accepted: 04.12 .2020

DOI: $10.35440 /$ hutfd. 808639 


\section{Giriş}

1978 yılında Alma-Ata'da gerçekleştirilen "Temel Sağlık Hizmetleri Birinci Konferansı"'nda her ülkenin vermesi gereken en az bakım (minimal care) kavramında sekiz faaliyetten bahsedilmekte; bu faaliyetlerden birisi de "Ana-çocuk sağlığı ve aile planlaması"dır (1). Günümüzden 40 yıl önce "Ana-çocuk sağlığı ve aile planlaması" hizmetlerinin önemi ortaya konulsa da; halen Dünya'da her yıl 600,000 'in üzerinde kadın, gebelik ve doğuma bağlı sorunlar sebebiyle hayatını kaybetmekte ve bu kayıpların birçoğu önlenebilir nedenlere bağlı gerçekleşmektedir (2). Prenatal bakım ya da antenatal bakım olarak da adlandırllan doğum öncesi bakım (DÖB), bu ölümlerin azaltılmasında en önemli araçlardan biridir. DÖB, eğitimli bir sağlık çalışanı tarafından anne ve fetüsün gebelik süresince düzenli aralıklarla gerekli muayene ve önerilerle izlenmesidir (3).

Yetersiz DÖB'ün düşük doğum ağırlığı, prematürite, ölü doğum, erken ve geç neonatal ölüm riski ile ilişkili olduğu bilinmektedir $(4,5)$. Ayrıca DÖB alan gebeler doğuma daha hazır oldukların $(6,7)$, kendine güvenlerinin ve daha rahat bir gebelik süreci geçirdiklerini (8), doğum sonrası kendi bakımları ve bebeğin bakımında daha az sorun yaşadıklarını (7) bildirmektedirler.

Sağlık Bakanlığı'nın yayınladığı "Doğum Öncesi Bakım Yönetim Rehberi"ne göre herhangi bir sorunu olmayan gebelere nitelikli en az dört izlem, belirli risk faktörleri olanların ise gereğinde izlem sayısının artırılması gerektiği belirtilmektedir (9).

Doğum öncesi bakımın niteliğini etkileyen faktörlerden biri de kadınların gebelik ve süreçleri hakkında bilgi düzeyleridir; bu sebeple DÖB'de gebelerin bilgilendirilmesine önem verilmelidir (8).

Türkiye Halk Sağlığı Kurumu'nun yayınlandığı 2014/28 Sayılı "Gebe Bilgilendirme Sınıfı Genelgesi" ile gebelere sunulan bilgilendirme ve danışmanlık hizmetlerinde etkin hizmet sunumu ve tüm ülkede standardın sağlanması amaçlanmaktadır. Bu genelge ile doğum öncesi bakımın niteliği artırmak için gebe sınıfları açılarak, gebelik, doğum ve doğum sonrası dönemlerine ilişkin bilgi sahibi olmaları ve bilinçli doğum yapmalarını sağlamak, yeni rolleri hakkında bilgi ve beceri kazandırmak amacıyla gebe bilgilendirme sınıfları açıması yolunda adımlar atılımışır (10).

Türkiye'de anne ve bebek ölümleri giderek azalmakta olduğu bilinmektedir (11). Ancak anne ve bebek ölümlerinde gelinen bu düzeyden daha iyi sonuçlara ulaşmak gittikçe zorlaşmaktadır. Anne ve bebek ölümlerinde azalmayı gerçekleştirmek için sağlık kurumlarında altyapı ve teknik donanım eksikliklerinin giderilmesinin yanında hizmet sunan sağlık personelinin bilgi ve becerilerinin de üst düzeyde tutulması gerekmektedir (9). Sağlık çalışanlarının bilgi ve becerilerinin hastalarının sağlıkları ve sağlık davranışları ile ilişkisi bilinmektedir (12). Annelerin hem kendileri hem de bebeklerinin bakımı için eğitim ve rehberlik gereksinimi olduğu; sağlık çalışanlarının da bu konuda sağlık eğitimi ve danışmanlığı verme rolü vardır (7). Sağlık personelleri eğitilip nitelik kazandırıldıkça gebe kadınları eğitebilir, motive edebilir ve onların sağlık destekçisi rolünü üstlenebilir. Gebe bilgilendirme sınıfları sayesinde de gebeler sağlık personelleriyle daha kolay iletişim kurabilir ve eğitimli sağlık personelleri gebeleri bilgi ve davranış yönünden destekleyebilirler.

Türkiye Nüfus ve Sağlık Araştırması (TNSA) 2018 verilerine göre Türkiye'de gerçekleşen doğumların yaklaşık üçte ikisi yüksek risk kategorisine girmektedir. Bu yüksek risk faktörleri ise şunlardır: İlk doğum, gebenin $<18$ ya da $>35$ yaş olması, doğum aralığının 2 yıldan kısa olması, üçten fazla doğum yapmaktır (13).

Literatür taramamızda hem dünyada hem Türkiye'de sağlık çalışanlarının aşılama, emzirme konularında eğitimlerinin değerlendirildiği çalışmalar görülse de $(14,15)$; sağlık çalışanlarına riskli gebelikler konusunda verilen eğitimlerin etkinliğinin değerlendirildiği bir çalışmaya rastlanmamıştır. Bu çalışmanın amacı sağlık personellerinin riskli gebelikler konusunda bilgi düzeylerinin belirlenmesi ve eğitim öncesisonrası bilgi düzeylerinin karşılaş̧ııılarak gerçekleştirilen eğitimin etkinliğinin değerlendirilmesidir.

\section{Materyal ve Metod Çalışmanın Yeri ve Bilgileri}

Bu çalışma 2020 yılında Şanlıurfa'da, Şanlıurfa II Sağlık Müdürlüğü ve Dünya Sağlık Örgütü (DSÔ) iş birliğinde gerçekleştirilen "Suriyeli Sığınmacı ve Türk Vatandaşı Kadınlarda Riskli Gebeliklerin Tanı ve Takibi (Diagnosis and Follow-up of Risk/High Risk Pregnancies of Women in Syrian and Host Communities)" projesi kapsamında yürütülen bir eğitim müdahale çalışmasıydı.

Eğitimler öncesinde eğitim konuları, içeriği ve kapsamı ile bilgi düzeylerini ölçmek için uygulanacak anketlerin oluşturulması amacıyla bir Perinatoloji uzmanı, iki Kadın HastaIıkları ve Doğum Uzmanı, bir Çocuk Sağlığı ve Hastalıkları Uzmanı, iki Halk Sağığı Uzmanı, bir tabip, bir fizyoterapist, bir diyetisyen ve bir psikoloğun katılığı üç adet toplantı düzenlendi. Eğitim materyallerinin hazırlanmasının ardından riskli gebelik eğitici eğitimi üç gün süreyle gerçekleştirildi. Eğitim programı ellişer dakikadan her gün altı konu olmak üzere riskli gebeliklerle ilgili on sekiz konuyu kapsamaktaydı. (Eğitim sunumları istek halinde yazarlardan talep edilebilir.)

Günlere göre eğitimde anlatılan konular: 1. gün: Gebelik Fizyolojisi, Gebelikte Meydana Gelen Değişiklikler, Gebelikte Tehlike İşaretleri, Bağışıklama, İlaç Kullanımı, Doğum Süreci, Doğum Ağrısıyla Başa Çıkma Yöntemleri, Doğum Algısı ve Doğum Korkusu, 2. gün: Doğuma Hazırlık, Lohusalık Dönemi Fizyolojik ve Psikolojik Değişiklikler, Loğusa izlem, Doğum Sonrası Bakım, Illetişim ve Etkili Sunum Teknikleri, Gebelikte Beslenme, Gebelikte Egzersiz, 3. gün: 
Riskli Gebelikler Algoritması, Gebelik Takibi, Rutin Tetkikler, Yeni doğanın Illk Bakımı, Aile Planlaması, Emzirme, Anne Sütü Önemi, Riskli Gebeliklerdir.

Riskli gebeliği olan gebelere eğitim vermek üzere, Şanlıurfa ilindeki 13 İlçe Sağlık Müdürlüğünün her birinden 1'i aktif 1'i yedek olmak üzere öncelikle ÇEKÜS biriminde görev alan sağlık çalışanlarından 2'şer hekim ve 2'şer ebe/hemşire belirlenerek çalışmaya katılmaya davet edildi. Evreni oluşturan 52 sağlık personeli olmasına rağmen bu personellerin bir kısmı Covid-19 pandemisinde de görev aldığı için çalışma sonunda 41 sağlık personeline eğitim verildi ve eğitim öncesi-sonrası anketler uygulandı. Bilgi düzeylerini değerlendirmek üzere uygulanan anket soruları Tablo 1'de gösterilmektedir.

Eğitimleri tamamlayan sağlık personelleri projenin devamında riskli gebeliği olan gebelere eğitimler düzenleyecektir.

Bu çalışmanın yürütülmesi için Harran Üniversitesi Klinik Araştırmalar Etik Kurulundan 13.07.2020 tarih ve 13 no'lu oturumda HRU/20.13.13 karar numarası ile etik kurul onayı alındı. Çalışmaya katılmayı kabul edenlerden aydınlatımış onam formu alındı.

\section{Değişkenler ve Anketler}

Veriler, veri toplama formu aracılığılla öz bildirim tekniği kullanılarak toplanmıştır. Veri toplama formu; demografik özellikler (cinsiyet, yaş), sağlık mesleği ile özellikleri (görevi, sağlıkla ilgili son öğrenim düzeyi, sağlık profesyoneli olarak çalıştığı süre, sağık mesleği boyunca riskli gebelik eğitim alma, mezuniyeti sonrasında riskli gebelik eğitimi alma), eğitim hakkındaki düşüncelerini (riskli gebeler için gebelik sınıfı gerekliliğini düşünme, tekrar riskli gebelikler eğitimine katılma isteği, eğitime verilen puan) içeren sorular ve riskli gebelikler konusunda bilgi düzeylerinin ölçüldüğü 30 sorudan oluşmaktaydı.

\section{İstatistiksel Yöntem}

Verilerin değerlendirilmesi ve analizi için IBM SPSS 21.0 (SPSS Inc., Chicago, Illinois, USA) istatistik paket programı kullanıldı. Kategorik değişkenler frekans (n) ve yüzde (\%); sayısal değişkenler ise ortalama \pm standart sapma, ortanca (en küçük-en büyük) değer ile ifade edildi. Sürekli değişkenlerin normal dağılıma uygunluğunun değerlendirirken değişim katsayısı, histogram ve Kolmogorov-Smirnov testi kullanıldı. Bağımlı iki gruptan elde edilen kategorik değişkenlerin karşılaştırımasında Mc-Nemar testi uygulandı. İstatistiksel anlamlılık için $p<0.05$ değeri kabul edildi.

\section{Bulgular}

Çalışmamıza katılan 41 sağlık çalışanının \%85,4'ü (n:35) kadın olup yaş ortalaması $29.78 \pm 6.86$; en küçük 23 yaş, en büyük 49 yaştı.

Katılımcıların \%43,9'u (n:18) doktor, \%41,5'i (n:17) ebe, $\% 14,6$ 'sı (n:6) hemşire olarak görev yapmaktaydı ve \%85,4'ü lisans derecesine sahipti. Çalışmaya katılan sağık çalışanlarının meslekteki tecrübe ortancası 2 yıl olup en küçük değer 3 ay en büyük değer 28 yıldı.

Tablo 1. Çalışmada uygulanan riskli gebelikler eğitici eğitimi değerlendirme anketi soruları

\begin{tabular}{|c|c|}
\hline Soru 1 & Endorfin hormonu doğum ağrısına sebep olur. \\
\hline Soru 2 & $\begin{array}{l}\text { Gebeye doğumda hareket özgürlüğü sağlamak doğumu kolaylaş- } \\
\text { tırır. }\end{array}$ \\
\hline Soru 3 & $\begin{array}{l}\text { Doğumda vajende olan yaralanmalar lohusalıkta idrar yolu enfek- } \\
\text { siyonunu artırmaktadır. }\end{array}$ \\
\hline Soru 4 & Doğum sırasında ayakta durma doğum ağrısını artııır. \\
\hline Soru 5 & Doğumda litotomi pozisyonu derin ven trombozunu artırır. \\
\hline Soru 6 & Doğum sonu kanamada öncelikle misoprostol uygulanmalıdır. \\
\hline Soru 7 & $\begin{array}{l}\text { Lohusalık döneminde kanama azaldıktan sonra tekrar loşi rubra } \\
\text { gelmesi normaldir. }\end{array}$ \\
\hline Soru 8 & $\begin{array}{l}\text { Gebelikte diyabet geçiren lohusalara 6.haftada OGTT yapılmall- } \\
\text { dır. }\end{array}$ \\
\hline Soru 9 & $\begin{array}{l}\text { Gebelikte Down Sendromu taramasında önce ikili test sonrasında } \\
\text { üçlü test yapılır }\end{array}$ \\
\hline Soru 10 & Gebelikte hipertansiyon tanısı için eşik değer $130 / 90$ mm Hg'dır \\
\hline Soru 11 & $\begin{array}{l}\text { NST takibine normal seyirli gebeliklerde } 35 \text {. Haftada başlanmalı- } \\
\text { dır. }\end{array}$ \\
\hline Soru 12 & $\begin{array}{l}\text { Gebelikte ilk trimesterda TSH düzeyleri fizyolojik olarak düşmek- } \\
\text { tedir. }\end{array}$ \\
\hline Soru 13 & $\begin{array}{l}\text { CRP yüksekliği halinde gebelikte hızlı bir şekilde ileri tetkik yapı- } \\
\text { malıdır. }\end{array}$ \\
\hline Soru 14 & Tüm gebelerde vitamin B12 düzeyi bakılmalı ve tedavi edilmelidir. \\
\hline Soru 15 & nsel grip aşısı tüm gebelere önerilmelidir. \\
\hline Soru 16 & duyulabilir. \\
\hline Soru 17 & $\begin{array}{l}\text { Gebelikte tam kan sayımında beyaz küre artışı 25-40 bin e kadar } \\
\text { ulaşabilir. }\end{array}$ \\
\hline Soru 18 & Gebelikte fizyolojik proteinüri olabilir. \\
\hline Soru 19 & Canlı aşılar emzirme döneminde kontrendikedir. \\
\hline Soru 20 & $\begin{array}{l}\text { HBV aşısı uygulanması gelişmekte olan fetüs açısından risk oluş- } \\
\text { turmamaktadır. }\end{array}$ \\
\hline Soru 21 & Glikozüri gebelikte bir tehlike işareti olarak değerlendirilmelidir. \\
\hline Soru 22 & Kötü obstetrik öyküsü olanlar perinatolojiye yönlendirilmelidir. \\
\hline Soru 23 & 35 yaş üstü her gebelik riskli gebeliktir. \\
\hline Soru 24 & $\begin{array}{l}\text { Gebelik takibinde hemogram ve idrar tahlili sadece illk } 2 \text { izlemde } \\
\text { bakılır. }\end{array}$ \\
\hline Soru 25 & Gebeliğin 16-20. haftalarında üçlü/dörtlü test önerilir. \\
\hline Soru 26 & $\begin{array}{l}\text { Gebelikten korunmada, OKS içilmesi } 1 \text { gün unutulduğunda yeni } \\
\text { kutuya başlanmalıdır. }\end{array}$ \\
\hline Soru 27 & RíA'yı emziren kadınlar kullanabilir. \\
\hline Soru 28 & Bebek her istediğinde emzirilmelidir. \\
\hline Soru 29 & Kolostrum, enfeksiyon ve alerjiden koruyan antikorlar içerir. \\
\hline Soru 30 & Sağılan anne sütü dondurmadan en fazla 3 gün saklanabilir. \\
\hline
\end{tabular}

Çalışmamıza katılanların \%31,7'si mesleki eğitimi boyunca riskli gebelik konusunda eğitim almadığını belirtti. Mezuniyeti sonrasında eğitim aldığını belirtenlerin oranı ise $\% 12,2$ 'ydi. Çalışmaya katılan sağlık çalışanlarının \%90,2'si (n:37) riskli gebeler için Gebe Sınıfı Eğitiminin gerekliliğine katıldığını belirtirken, \%7,4'ü (n:3) katılmadığını, \%2,4'ü (n:1) kararsız olduğunu belirtmişti.

Eğitici eğitimi sonrasında, katılımcıların \%78,0'i (n:32) ileride tekrar riskli gebelikler eğitimine katımak istediğini, $\% 14,6$ 'sı (n:6) katılmak istemediğini, \%7,4'ü (n:3) katıma isteğinde kararsız olduğunu belirtti.

Eğitici eğitimi sonrasında, katılımcılar yapılan eğitime 10 üzerinden ortalama $7.83 \pm 1,50$ puan verdi. 
Tablo 2. Eğitime katılan sağlık çalışanlarının özellikleri ve eğitim hakkındaki düşünceleri

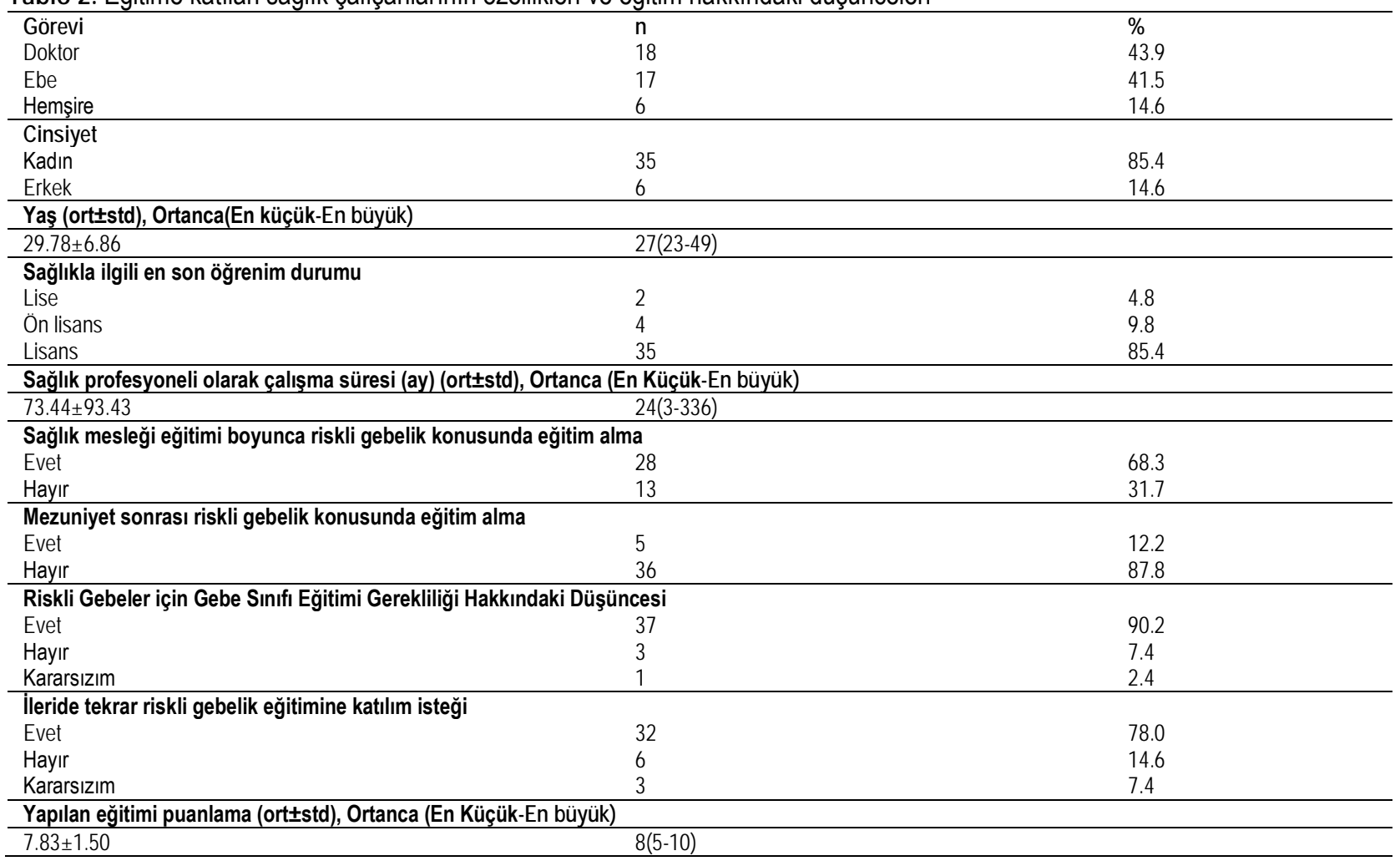

Tablo 3. Çalışmaya katılan sağlık çalışanlarının eğitim öncesi ve eğitim sonrası riskli gebelikler konusu üzerine bilgi düzeyleri ve değişimi

\begin{tabular}{|c|c|c|c|c|c|c|c|}
\hline & \multicolumn{3}{|c|}{ Eğitim Öncesi } & \multicolumn{3}{|c|}{ Eğitim Sonrası } & \multirow[t]{2}{*}{ p değeri } \\
\hline & Katilıyorum & Katılmıyorum & Kararsızım & Katılıyorum & Katılmıyorum & Kararsızım & \\
\hline \multicolumn{8}{|c|}{ Aşağıdaki sorularda "Katılıyorum" seçeneği Doğru Cevaptır. } \\
\hline Soru 2 & $73.2 \%$ & $14.6 \%$ & $12.2 \%$ & $87.8 \%$ & $9.8 \%$ & $2.4 \%$ & 0.109 \\
\hline Soru 3 & $78 \%$ & $14.6 \%$ & $7.3 \%$ & $90.2 \%$ & $2.4 \%$ & $7.3 \%$ & 0.125 \\
\hline Soru 5 & $14.6 \%$ & $41.5 \%$ & $43.9 \%$ & $58.5 \%$ & $26.8 \%$ & $14.6 \%$ & $<0.001$ \\
\hline Soru 8 & $29.3 \%$ & $36.6 \%$ & $34.1 \%$ & $39 \%$ & $46.3 \%$ & $14.6 \%$ & 0.481 \\
\hline Soru 12 & $48.8 \%$ & $7.3 \%$ & $43.9 \%$ & $85.4 \%$ & $12.2 \%$ & $2.4 \%$ & 0.003 \\
\hline Soru 15 & $41.5 \%$ & $31.7 \%$ & $26.8 \%$ & $70.7 \%$ & $24.4 \%$ & $4.9 \%$ & 0.023 \\
\hline Soru 17 & $29.3 \%$ & $22 \%$ & $48.8 \%$ & $56.1 \%$ & $22 \%$ & $22 \%$ & 0.013 \\
\hline Soru 20 & $36.6 \%$ & $22.0 \%$ & $41.5 \%$ & $56.1 \%$ & $34.1 \%$ & $9.8 \%$ & 0.021 \\
\hline Soru 22 & $82.9 \%$ & $4.9 \%$ & $12.2 \%$ & $97.6 \%$ & $0 \%$ & $2.4 \%$ & 0.031 \\
\hline Soru 23 & $82.9 \%$ & $7.3 \%$ & $9.8 \%$ & $92.7 \%$ & $7.3 \%$ & $0 \%$ & 0.219 \\
\hline Soru 25 & $75.6 \%$ & $7.3 \%$ & $17.1 \%$ & $85.4 \%$ & $7.3 \%$ & $7.3 \%$ & 0.344 \\
\hline Soru 27 & $78 \%$ & $9.8 \%$ & $12.2 \%$ & $90.2 \%$ & $4.9 \%$ & $4.9 \%$ & 0.180 \\
\hline Soru 28 & $78 \%$ & $17.1 \%$ & $4.9 \%$ & $95.1 \%$ & $4.9 \%$ & $0 \%$ & 0.016 \\
\hline Soru 29 & $87.8 \%$ & $7.3 \%$ & $4.9 \%$ & $100 \%$ & $0 \%$ & $0 \%$ & $<0.001$ \\
\hline Soru 30 & $53.7 \%$ & $24.4 \%$ & $22.0 \%$ & $78.0 \%$ & $19.5 \%$ & $2.4 \%$ & 0.021 \\
\hline \multicolumn{8}{|c|}{ Aşağıdaki sorularda "Katılmıyorum" seçeneği Doğru Cevaptır. } \\
\hline Soru 1 & $7.3 \%$ & $51.2 \%$ & $41.5 \%$ & $19.5 \%$ & $75.6 \%$ & $4.9 \%$ & 0.002 \\
\hline Soru 4 & $19.5 \%$ & $46.3 \%$ & $34.1 \%$ & $17.1 \%$ & $75.6 \%$ & $7.3 \%$ & 0.004 \\
\hline Soru 6 & $19.5 \%$ & $19.5 \%$ & $61 \%$ & $22 \%$ & $43.9 \%$ & $34.1 \%$ & 0.021 \\
\hline Soru 7 & $26.8 \%$ & $22 \%$ & $51.2 \%$ & $34.1 \%$ & $43.9 \%$ & $22 \%$ & 0.049 \\
\hline Soru 9 & $90.2 \%$ & $2.4 \%$ & $7.3 \%$ & $51.2 \%$ & $46.3 \%$ & $2.4 \%$ & $<0.001$ \\
\hline Soru 10 & $61 \%$ & $29.3 \%$ & $9.8 \%$ & $19.5 \%$ & $78 \%$ & $2.4 \%$ & $<0.001$ \\
\hline Soru 11 & $36.6 \%$ & $31.7 \%$ & $31.7 \%$ & $29.3 \%$ & $61 \%$ & $9.8 \%$ & 0.002 \\
\hline Soru 13 & $73.2 \%$ & $4.9 \%$ & $22 \%$ & $43.9 \%$ & $56.1 \%$ & $0 \%$ & $<0.001$ \\
\hline Soru 14 & $85.4 \%$ & $2.4 \%$ & $12.2 \%$ & $22 \%$ & $75.6 \%$ & $2.4 \%$ & $<0.001$ \\
\hline Soru 16 & $29.3 \%$ & $26.8 \%$ & $43.9 \%$ & $36.6 \%$ & $51.2 \%$ & $12.2 \%$ & 0.021 \\
\hline Soru 18 & $48.8 \%$ & $19.5 \%$ & $31.7 \%$ & $39 \%$ & $58.5 \%$ & $2.4 \%$ & $<0.001$ \\
\hline Soru 19 & $53.7 \%$ & $26.8 \%$ & $19.5 \%$ & $53.7 \%$ & $41.5 \%$ & $4.9 \%$ & 0.180 \\
\hline Soru 21 & $73.2 \%$ & $12.2 \%$ & $14.6 \%$ & $39 \%$ & $58.5 \%$ & $2.4 \%$ & $<0.001$ \\
\hline Soru 24 & $9.8 \%$ & $70.7 \%$ & $19.5 \%$ & $4.9 \%$ & $92.7 \%$ & $2.4 \%$ & 0.022 \\
\hline Soru 26 & $9.8 \%$ & $73.2 \%$ & $17.1 \%$ & $7.3 \%$ & $82.9 \%$ & $9.8 \%$ & 0.289 \\
\hline
\end{tabular}




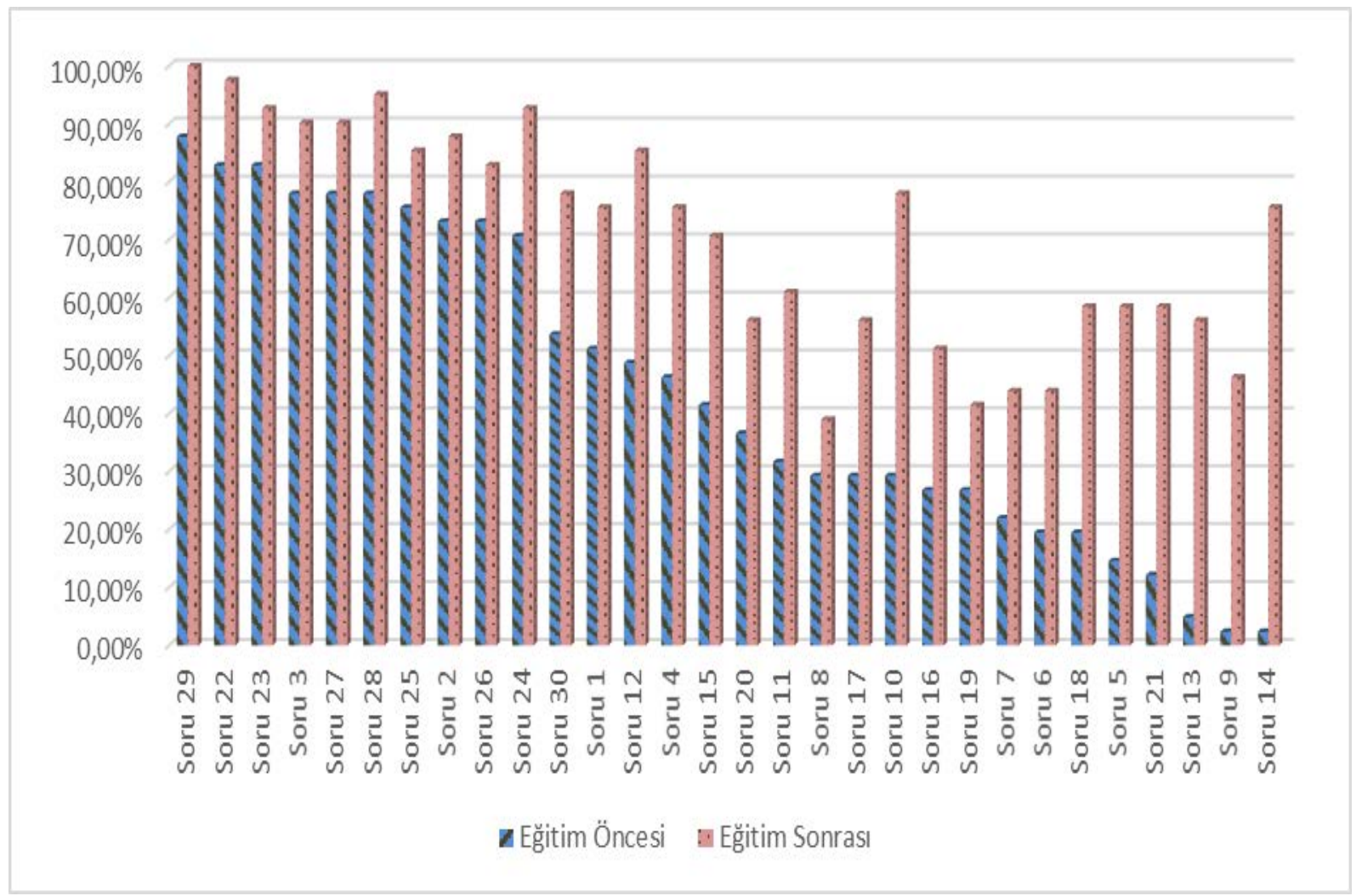

Şekil 1. Çalışmaya katılan sağık çalışanlarının eğitim öncesi ve eğitim sonrası riskli gebelikler konusu üzerine bilgi düzeyleri ve değişimi

Tablo 3 ve Şekil 1'de katılımcıların bilgi düzeylerini ölçen sorulara eğitim öncesi ve sonrası verilen cevaplarının yüzdesi gösterilmektedir. Eğitim sonrasında otuz soru için de doğru cevap yüzdelerinde artış görülmektedir. Otuz sorudan 22 'sinde doğru yanıtlarda \%15-73 arasında istatistiksel olarak anlamlı düzeyde artı̧̧ ( $\mathrm{p}:<0.05) ; 8$ soruda ise istatistiksel olarak anlamsız bulunsa da doğru yanıtlarda \%10-15 arasında artış görülmektedir ( $p:>0.05$ ).

\section{Tartışma}

Bu çalışma Türkiye'nin sosyoekonomik durumu görece düşük bir şehri olan Şanlıurfa'da yapılmıştır. Alptekin ve Koruk, Şanlıurfa'da gerçekleştirdiği çalışmada gebeliklerin $\% 54.7$ 'sinin plansız olduğu ve gebelerin $\% 45$.3'ünün gebeliğe bağlı en az bir sağlık sorunu olduğunu bildirmektedir (16). Bucak ve ark. Şanlıurfa'da yaptıkları çalışmada gebelerin \%28.8'inde düşük öyküsü, \%8.2'sinde ölü doğum öyküsü, \%73.3'ünde 19 yaş altı doğum öyküsü, \%62.8'sinde iki yıldan kısa aralıkla gerçekleşen doğum öyküsü olduğunu bildirmektedir (17). TNSA 2018 çalışmasında da Türkiye'de gerçekleşen doğumlarda annelerin üçte ikisinin yüksek risk faktörlerinden birini taşıdığı bildirilmektedir (13). Kurçer ve ark. Şanlıurfa'da hem gebelerin hem de bebeklerin aşı oranlarının düşük olduğunu göstermiştir (18). Güner ve Koruk'un Şanlıurfa'da gerçekleştirdiği çalışmada ilk 6 ay sadece anne sütü verme oranının \%26.5 olarak çok düşük düzeyde olduğu bildirilmektedir (19). Benzer sosyo- kültürel toplumlarda yapılan çalışmalarda da gebelerin gebelik süreci hakkında bilgi düzeylerinin düşük olduğu görülmektedir (20). Bu çalışmalar Şanlıurfa ilinde gebelerin riskli gebelikler ve gebelik süreci hakkında eğitim ve yardıma ihtiyaç duyduğunu ortaya koymaktadır. Çalışmamıza katılan sağlık çalışanlarının \%90,2'si riskli gebeliği olan kadınlar için gebelik eğitiminin gerekli olduğunu düşündüğünü bildirmiştir.

Sağılk Bakanlığı'nın yayınladığı "Doğum Öncesi Bakım Yönetim Rehberi"nde herhangi bir riski olmayan gebelerin nitelikli en az dört bakım alması, herhangi bir risk faktörü olanların ise saptanan riske göre uzman görüşü alınarak izlem sayısının artırıması gerektiği bildirilmektedir (9). Özsoy ve ark. yaptıkları çalışmada gebelerin ortalama $10 \mathrm{iz}-$ lemi yapıımasına karşın sadece \%4.1'inin antenatal bakımları sırasında emzirme konusunda eğitim aldıklarını bildirmiştir (15). Joshi ve ark. çalışmalarında gebelerin kolostrum hakkında kısmen bilgi sahibi olduklarını ve bilgi düzeylerinin daha da artırabileceğini bildirmektedir (21). Benzer bulgular preeklampsi gibi gebelikte risk ortaya çıkarabilecek durumlar için de gösterilmiştir (22). Mouzan ve ark. personel eğitimleri ve topluma yönelik sağlık eğitimleri yoluyla hem bilgi düzeylerinin hem de aşı yaptırma oranlarının arttığını bildirmektedir (23). Prekonsepsiyonel müdahaleler yoluyla ek ilaç kullanımı (Demir, folik asit), aşılama, obezite kontrolü, diabet yönetimi, tetkik yaptırma konusunda uyumun arttığı bildirilmektedir (24). Bu bilgiler, gebelerin bilgi düzeylerinin yükseltilmesi ve daha iyi sağlık 
çıktıları elde edebilmek için, nitelikli sağlık personellerinin rehberliğine intiyaç duyduklarını göstermektedir.

Broughton ve ark. çalışmasında sağlık çalışanlarının üçte birinin aşıların etkinliği ve güvenliğine inanmadığını bildirmektedir (25). Bu çalışmada sağlık çalışanlarının yaklaşık yarısı aşılara ilişkin sorulara eğitim öncesinde doğru yanıt vermişti ve eğitim sonrası bilgi düzeylerinde artış görüldü. Elitok ve ark. çalışmalarında sağlık çalışanlarının \%50'sinin $D$ vitamini, \%6'sının ise Bakanlığın önerilerine uygun dozda D vitamini önerdiğini göstermiştir (26). Sağlık Bakanlığı'nın yürürlükte olan programlarına rağmen sağlık çalışanlarının öneri oranlarının düşük olduğu görülmektedir. Bu sebeple sağlık çalışanlarının bilgi ve becerilerinin geliştirilmesi ve stratejilere uyumunu artırmak amacıyla eğitim programlarının düzenlenmesi çok büyük önem arz etmektedir. Bu çalışmada sağlık personellerinin anne sütü ve bebeğin beslenmesi ile ilgili sorulara eğitim öncesinde $\% 70$ civarında doğru cevaplar verseler de eğitimle bilgi düzeylerinin daha da yükseldiğini göstermektedir. Vishram ve ark. çalışmalarında eğitim almış sağlık personellerinin gebelere önerilerde bulunmaya daha yatkın ve kendilerinden daha emin olduklarını bildirmiştir (14). Malta ve ark. gerçekleştirdikleri eğitimsel müdahale çalışmasında eğitim alan sağlık çalışanlarının fiziksel egzersiz ve beslenme hakkında bilgi düzeylerinin eğitim almayanlara göre daha yüksek olduğunu bildirmiştir (12). Heyes ve ark. çalışmasında birçok sağlık personelinin mesleklerine başladıktan sonra doğum öncesi bakım hakkında eğitim almadığını belirtmektedir (27). Bizim çalışmamızda da sağlık çalışanlarının \%87,8'i mezuniyetleri sonrasında riskli gebelikler konusunda eğitim almadığını belirtmekteydi. Sağ ık çalışanlarının riskli gebelikler ve gebelik konularında bilgi düzeylerinin düşük olması, iyi gebelik çıktılarının elde edilmesi ve gebelere iyi bir doğum öncesi bakım sunulmasının önünde büyük bir engeldir.

Bu çalışmada yapılan eğitim müdahalesiyle sağlık çalışanlarının riskli gebelikler konusunda 30 sorudan 22'sinde bilgi düzeylerinin \% 15-73 arasında anlamlı düzeyde arttığı; diğer 8 soruda ise anlamlı olmasa da \% $10-15$ arasında artış gösterdiği bulunmuştur. Bu nedenle gerçekleştirilen eğitim müdahalesi etkili bulunmuştur. Çalışmamıza katılan sağlık çalışanlarının \%78,0'i ileride tekrar riskli gebelik eğitimine katılmak istediğini belirtmekteydi. Yapılan eğitime verilen ortalama puan $7.83 \pm 1.50$ olup eğitimin faydalı olduğunu düşündükleri yönünde değerlendirilebilir.

Yüz yüze yapılan eğitimlerde zaman sorunu yaşanması, toplu eğitimleri engelleyebilecek (Covid-19 vb. pandemiler) durumlar göz önüne alınarak farklı sağlık ve hizmet içi eğitim modelleri de kurgulanabileceği göz önünde bulundurulmalıdır. Bilgi iletişim teknolojilerindeki gelişmeler ve bireyin öğrenmeye hazır olduğu zaman web ortamındaki bilgiye defalarca ulaşma olasılığı ve web ortamında yapılan eğitimlerin klasik eğitimlere göre daha düşük maliyetli olması gibi özellikler sebebiyle internet üzerinden eğitim modelleri de başarıı bir şekilde kullanılabilir (28).

Bu çalışmanın bazı sınırıııkları vardır. Birincisi, çalışma Şanlıurfa ilinde 13 İlçe Sağlık Müdürlüğünde çalışan 41 sağlık çalışanı ile katılım gönüllülüğü esasına göre yapımıştır; katılımcıların neredeyse tamamı İlçe Sağlık Müdürlüklerinin Çocuk, Kadın, Ergen ve Üreme sağlığı biriminde çalışmaktaydı ve bu nedenle bilgi düzeyleri normalden yüksek olabilir. İkinci bir sınırlıık olarak çalışmamızda örneklem büyüklüğü hesaplanmadı ve örneklem seçilmedi; bu sebeple çalışma tüm sağlık çalışanlarına veya Şanlıurfa iline genellenemez. Üçüncü bir sınırlılık olarak da çalışma 41 sağlık çalışanı üzerinde yapıldığı için bazı sorularda bilgi düzeyindeki artış istatistiksel olarak anlamlı bulunmadı; bu katılımcı sayısına bağlı olarak çalışmanın gücünün düşük olmasına bağlı olabilir.

Sonuç olarak eğitim sonrasında 30 sorudan 22'sinde bilgi düzeyinde \%15-73 arasında anlamlı artış ve 8 soruda ise \%10-15 arasında anlamlı olmayan artış görülmektedir. Bilgi düzeylerinde artış görüldüğü için gerçekleştirilen eğitim müdahalesi etkili bulunmuştur. Gebe sınıfı eğitimlerini gerçekleştirecek birinci basamak sağlık ekiplerine yönelik verilecek eğitimlerle sağlık profesyonellerinin bilgi, beceri ve uygulamalarını geliştirmek mümkündür. Ayrıca bu sonuçlarımız, mevcut çalışmanın bir parçası olduğu daha büyük bir araştırma projesinde faydalı olacaktır. Çalışmamızın bir sonraki adımında eğitim verdiğimiz sağlık personelleri aracılığıyla İlçe Sağlık Müdürlükleri bünyesinde oluşturulan gebe bilgilendirme sınıflarında öncelikle riskli gebeliği olanlara eğitimler verilecektir.

\section{Açıklamalar}

Çıkar çatışması beyanı: Yazarlar çıkar çatışması olmadığını bildirmişlerdir.

Finansal destek: Bu çalışma "Suriyeli Sığınmacı ve Türk Vatandaşı Kadınlarda Riskli Gebeliklerin Tanı ve Takibi (Diagnosis and Follow-up of Risk/High Risk Pregnancies of Women in Syrian and Host Communities)" projesinin bir parçası olarak DFC sözleşmesi kapsamında (Proje Numarası: 202498071) DSÖ iş birliği ile finanse edilmiştir.

Etik kurul onayı: Bu çalışmanın yürütülmesi için Harran Üniversitesi Klinik Araştırmalar Etik Kurulundan 13.07.2020 tarih ve 13 no'lu oturumda HRU/20.13.13 karar numarası ile etik kurul onayı alındı.

\section{Kaynaklar}

1. Öztek Z. Temel Sağlık Hizmetleri 1978-2018. Trakya Üniversitesi Matbaası: Halk Sağlığı Uzmanları Derneği (HASUDER); 2018.

2. Kurt AK, Set T, Ateş E. Birinci Basamak Sağlık Hizmetleri ile Gebelik Tanısı ve Takibi Arasındaki İlişki. Eurasian Journal of Family Medicine 2019;8(4):175-81.

3. Sönmez Y. Doğum öncesi bakım hizmetleri. Sürekli Tıp Eğitimi Dergisi 2007;16(1):9-12.

4. Ashraf-Ganjoei T, Mirzaei F, Anari-Dokht F. Relationship between prenatal care and the outcome of pregnancy in low-risk pregnancies. Open J Obstet Gynecol 2011;1(3):109-12.

5. Partridge S, Balayla J, Holcroft CA, Abenhaim HA. Inadequate prenatal care utilization and risks of infant mortality and poor birth outcome: 
a retrospective analysis of $28,729,765$ US deliveries over 8 years. American journal of perinatology 2012;29(10):787-94.

6. Mete S, Çiçek Ö, Aluş Tokat M, Çamlıbel M, Uludağ E. Doğuma Hazırlık Sınıflarının Doğum Korkusu, Doğum Tercihi ve Doğuma Hazır Oluşluğa Etkisi. Turkiye Klinikleri Hemsirelik Bilimleri 2017;9(3):201-6.

7. Altuntuğ K, Emel E. Sağlık eğitiminin annelerin taburculuğa hazır oluş, doğum sonu güçlük yaşama ve yaşam kalitesine etkisi. Hemşirelikte Araştırma Geliştirme Dergisi 2013;15(2):45-56.

8. Akın B, Çeber Turfan E. Doğuma Hazırlık Eğitimi Alan ve Almayan Gebelerin Doğumdan Memnuniyetlerinin Değerlendirilmesi. Uluslararası Hakemli Kadın Hastalıkları ve Anne Çocuk Sağlı̆ı Dergisi 2016(8):1-16.

9. T.C. Sağlık Bakanlığı Halk Sağlığı Genel Müdürlüğü. Doğum Öncesi Bakım Yönetim Rehberi. Ankara. 2014.

10. T.C. Sağlık Bakanlığı 2014/28 Sayılı "Gebe Bilgilendirme Sınıfı Genelgesi" Erişim yeri: https://dosyaism.saglik.gov.tr/Eklenti/12616,20140925-85-hskdan-gebe-bilgilendirme-sinifi-hakkindagenelge-2014-28pdf.pdf?0 Erişim tarihi: 15.08.202.

11. Köksal SS, Sipahioğlu NT, Yurtsever E, Vehid S. Comparison of Turkey and European Countries According to Basic Health Indicators. Turkish Journal of Family Medicine and Primary Care 2016;10(4):20512.

12. Malta MB, Carvalhaes MAdBL, Takito MY, Tonete VLP, Barros AJ, de Lima Parada CMG, et al. Educational intervention regarding diet and physical activity for pregnant women: changes in knowledge and practices among health professionals. BMC pregnancy and childbirth 2016;16(1):1-9.

13. Hacettepe Üniversitesi Nüfus Etütleri Enstitüsü. Türkiye Nüfus ve Sağlık Araştırması (2018). Ankara:2018.

14. Vishram B, Letley L, Jan Van Hoek A, Silverton L, Donovan $H$, Adams $C$, et al. Vaccination in pregnancy: attitudes of nurses, midwives and health visitors in England. Human vaccines \& immunotherapeutics 2018;14(1):179-88.

15. Gökdemirel SÖ, Bozkurt G, Karanisoğlu H. Antenatal İzlemler Sırasında Gebelere Emzirme Eğitimi Verilme Durumu. Sürekli Tıp Eğitimi Dergisi 2011;20(2):66-9.

16. Alptekin PÇ, Koruk F. Şanlıurfa'da Gebe Kadınların İlaç Kullanım Alışkanlıkları ve Etkileyen Faktörler. Journal of Harran University Medical Faculty 2020;17(1):28-32.

17. Bucak FK, Özcanarslan F, Demir M. Şanlıurfa kadın hastalıkları ve doğum hastanesine başvuran gebelerde anemi sıklığı ve ilişkili faktörler. Sağlık Akademisyenleri Dergisi 2017;4(2):103-9.

18. Kurçer MA, Şimşek Z, Solmaz A, Dedeoğlu Y, Gülel R. Şanlıurfa Harrankapı Sağlık Ocağı Bölgesi'nde 0-2 yaş çocuk ve gebelerde aşılanma oranları ve aşılanmada sorunlar. Harran Üniversitesi Tıp Fakültesi Dergisi 2005;2(2):10-5.

19. Güner Ö, Koruk F. Şanlıurfa'da 0-6 aylık bebeklerin sadece anne sütü alma durumları ve etkileyen faktörler. Harran Üniversitesi Tıp Fakültesi Dergisi 2019;16(1):111-6.

20. Al Otaiby T, Jradi H, Bawazir A. Antenatal Education: An Assessment of Pregnant Women Knowledge and Preferences in Saudi Arabia, Women's Heal. Care 2013;2(4):1000139.

21. Joshi SK, Barakoti B, Lamsal S. Colostrum feeding: knowledge, attitude and practice in pregnant women in a teaching hospital in Nepal. WebmedCentral:International Journal of Medicine and Molecular Medicine 2012;3(8):WMC003601.

22. Fondjo LA, Boamah VE, Fierti A, Gyesi D, Owiredu E-W. Knowledge of preeclampsia and its associated factors among pregnant women: a possible link to reduce related adverse outcomes. BMC pregnancy and childbirth 2019;19(1):456.

23. Mouzoon ME, Munoz FM, Greisinger AJ, Brehm BJ, Wehmanen OA, Smith $F A$, et al. Improving influenza immunization in pregnant women and healthcare workers. The American journal of managed care 2010;16(3):209-16.

24. Dunlop AL, Jack B, Frey K. National recommendations for preconception care: the essential role of the family physician. The Journal of the American Board of Family Medicine 2007;20(1):81-4.

25. Broughton DE, Beigi RH, Switzer GE, Raker CA, Anderson BL. Obstetric health care workers' attitudes and beliefs regarding influenza vaccination in pregnancy. Obstetrics \& Gynecology 2009;114(5):981-7.

26. Elitok GK, Bülbül L, Evci M, Zübarioğlu U, Toraman T, Acar DB, et al. Sağık çalışanlarının annelere $D$ vitamini desteği ile ilgili bilgi ve tutumlarının değerlendirilmesi. Şişli Etfal Tıp Bülteni 2017;51(1):48-55.

27. Heyes T, Long S, Mathers N. Preconception care: practice and beliefs of primary care workers. Family Practice 2004;21(1):22-7.

28. Demir Y, Gözüm S. Sağık eğitiminde yeni yönelimler; web destekli sağlık eğitimi. Dokuz Eylül Üniversitesi Hemşirelik Yüksekokulu Elektronik Dergisi 2011;4(4):196-203. 